\title{
Comparison of knowledge and practice regarding colostrum feeding among mothers in rural and urban area
}

\author{
Sirivella Tejaswini ${ }^{1}$, Bhavani Bangarkodi Balakrishna ${ }^{2 *}$
}

\begin{abstract}
${ }^{1}$ Department of Community Health Nursing, The Oxford College of Nursing, Hongasandra, Bengaluru, Karnataka, India

${ }^{2}$ Department of Child Health Nursing, Sri Shankara College of Nursing, Shankarapuram, Bengaluru, Karnataka, India
\end{abstract}

Received: 20 April 2021

Revised: 12 May 2021

Accepted: 13 May 2021

\author{
*Correspondence: \\ Dr. Bhavani Bangarkodi Balakrishna, \\ E-mail: bhavanibb@yahoo.com
}

Copyright: ( ) the author(s), publisher and licensee Medip Academy. This is an open-access article distributed under the terms of the Creative Commons Attribution Non-Commercial License, which permits unrestricted non-commercial use, distribution, and reproduction in any medium, provided the original work is properly cited.

\begin{abstract}
Background: Basic food of infant is mother's milk. Breast feeding should be initiated within the first half an hour of birth. The first milk is the most suitable feed for the newborn. Colostrum is very important for growth, development and protection from infections in infants. The importance of colostrum is still not known to many mothers and caregivers. This study aimed to compare the knowledge and practice regarding colostrum feeding among mothers in urban and rural area.

Methods: A descriptive approach and comparative survey design was adopted for the study. Data was collected from 150 mothers (75 each from urban and rural area) having infants of birth to 6 months age. Data was collected using a performa with items on socio-demographic varibles, a structured questionnaire to assess knowledge and a practice questionnaire regarding colostrum feeding.

Results: $46.7 \%$ urban and 48\% rural had moderate level of knowledge and $22.7 \%$ mothers from rural had poor knowledge. The urban mothers were more aware about colostrum feeding and its importance than rural mothers. Majority of the mothers (92\% urban, $89.3 \%$ rural) practiced colostrum feeding. Comparison of knowledge and practice showed statistically significant difference between mothers of urban and rural area.

Conclusions: Knowledge regarding colostrum feeding was inadequate and improper breast feeding practices were found in both urban and rural area. Urban area mothers had more knowledge and better feeding practices compared to mothers of rural area. There is an ongoing need for individual and community awareness programmes regarding importance of colostrum feeding.
\end{abstract}

Keywords: Colostrum, Mothers, Knowledge, Practice, Urban, Rural

\section{INTRODUCTION}

The first breast milk produced after giving birth is known as colostrum. Colostrum is very important component of breast milk and lays the foundation for the immune system. It contains protective antibodies to prevent infections in the newborn, vital nutrients for tissue development, growth and energy. Colostrum has been used for various illnesses in India for many years. The medical importance was described in the ancient medicine of Ayurveda. In US colostrum was in use for its anti-bacterial activity before the discovery of antibiotics. Colostrum has been used for treatment of rheumatoid arthritis and anti-polio vaccine was prepared from bovine colostrum. Colostrum has been reported to be very safe and effective in its use for repair of tissue as well as for enhancing the immunity. ${ }^{1}$

Breast feeding should be initiated within the first half an hour of birth. The first milk is the most suitable food for the newborn. Colostrum is very rich in proteins, carbohydrates, vitamin $\mathrm{A}$ and sodium chloride. It also 
contains lower amounts of lipids and potassium than normal milk. Newborns have a premature digestive system which suits the low-volume concentrated form of the nutrient supply system of colostrum. The laxative effect of colostrum encourages passage of the baby's first stool, meconium. This helps to clear excess bilirubin, which is produced in large quantities at birth and helps prevent jaundice. It contains various immunoglobulins like $\operatorname{IgA}, \operatorname{IgG}$ and $\operatorname{IgM}$. Other immune components of colostrum are lactoferrin, lysozyme, lactoperoxidase, complement and proline-rich peptide (PRP). It also contains various cytokines and growth factors. PRP helps fight against various viral infections like herpes viruses and HIV, bacterial and viral infections which are difficult to treat, various cancers, asthma, allergies and autoimmune diseases. It helps to reduce one of the leading causes of death in India like diarrhoea and ARI. ${ }^{2}$

The importance of colostrum is known to the limited population. There are still many people who believe that colostrum is a harmful substance which should be discarded. It is thought to be an unwanted substance related to ill health. There are certain barriers preventing the feeding of colostrum to the newborn babies. Maternal barriers are that many mothers lack knowledge about the importance of early initiation of breastfeeding and the benefits of colostrum feeding. Some mothers dislike the colour of colostrum. They even discard it themselves and also on the advice of family members. There is also misinterpretation that breast milk does not come in the first few days after delivery and it is insufficient for the baby's needs. Prolonged labour and surgical deliveries are also the hindrance to colostrum feeding. Neonatal barriers include neonatal illness which is one of the major barriers to colostrum feeding. Some babies are not able to suck breast milk due to illness, deformities or other reasons. ${ }^{3}$

Cultural practices have its effects on colostrum feeding, as they believe it to be old milk that has been present in the mother and perceive it as unfit for the baby, hence it should be thrown out. The formula feeding has been considered as the status symbol for the mothers in many urban areas. The mistaken notions about the practice of the colostrum feeding, adversely affect the body form and the growth regarding formula feed as being superior in composition to breast milk. Lack of will to breast feed the child by the mother is another contributing factor. ${ }^{4}$

The practice of giving pre-lacteal feeds, discarding colostrum as per the elders advice and delay in the initiation of breastfeeding has been reported in studies by Ashwini et al in both urban and rural areas. ${ }^{5}$ Comparative studies on knowledge and practices regarding colostrum are limited. Hence, this study was aimed to compare the knowledge and practice regarding colostrum feeding among mothers in urban and rural area, to find co-relation between knowledge and practice regarding colostrum feeding and to determine the association between knowledge, practice and socio-demographic variables of mothers.

\section{METHODS}

A descriptive approach and comparative survey design were adopted for the study. The study was done between November 2018 to April 2019. The setting of the study was primary health centres under urban and rural area in Bengaluru, Karnataka, India. In the urban area Begur Primary health centre, Bengaluru South and in the rural area Chandapura Primary health centre was the setting for data collection. The sample comprised of 150 mothers with infants who had undergone normal or caesarean delivery selected using non-probability purposive sampling technique. The inclusion criteria were, mothers having infants from birth to 6 months, mothers who were willing to participate in this study and those could read and write Kannada or English.

Data collection tools included a performa for collecting socio-demographic data. A structured questionnaire to assess knowledge regarding colostrum feeding with 20 multiple choice items. Each item was scored one for correct answer and zero for incorrect answer with a total possible score of 20. It was arbitrarily categorized as adequate knowledge $(>75 \%)$, moderate knowledge (50$75 \%)$, inadequate knowledge $(<50 \%)$. To assess colostrum feeding practice a questionnaire with a yes or no response was used. A score of one was given for the yes and zero for no answer. The tool was validated by experts in the field of nursing and medicine. Official permission was obtained from the concerned authority of the selected primary health centers. Consent was taken from the mothers. The data collected were entered in SPSS and analyzed using descriptive and inferential statistics.

\section{RESULTS}

In the present study, $58.7 \%$ mothers of urban and $50.7 \%$ from rural area were in the age group of 18-25 years. Around $40 \%$ were in the age group of 26-35 years in both urban and rural areas. Educational qualification of $30 \%$ mothers in urban and $48 \%$ in rural areas was primary education, $28 \%$ each in both areas had completed secondary education. Around 57\% mothers were housewives in both urban and rural area, 57.3\% mothers of urban area reported their source of information on colostrum feeding as health professionals whereas $49.3 \%$ mothers in the rural area availed information from family or friends and $60 \%$ mothers belonged to joint family in both the groups.

The birth order of the present child was second child in urban mothers $(42.7 \%)$ and rural mothers $(53.3 \%)$ first child. Urban mothers $(36.0 \%)$ were persuaded to give colostrum milk by health personnel and rural mothers $(48.0 \%)$ were persuaded by elders in the family (Table 1 ). 
Level of knowledge regarding colostrum feeding among urban and rural mothers showed that less than fifty

colostrum feeding. Most mothers (46.7\% urban, $48 \%$ rural) had a moderate level of knowledge, $22.7 \%$ mothers from rural area had inadequate knowledge (Table 2).

With regard to colostrum feeding practices majority of the mothers (92\% urban, $89.3 \%$ rural) area reported giving colostrum feeding, most ( $86.7 \%$ urban, $72 \%$ rural) of the mothers reported feeding colostrum within one hour after delivery. Although more than $75 \%$ mothers did not practice giving any pre-lacteal feeds, but around percent mothers in urban and less than thirty percent rural area had an adequate level of knowledge regarding

$21.3 \%$ urban mothers and $22 \%$ mothers gave pre-lacteal feeds to newborn. Burping after feed was done by $88 \%$ mothers from urban area, whereas nearly half the mothers from rural area did not carry out burping. Around 66.7\% and $72 \%$ mothers reported feeding the baby during illness in urban and rural area respectively, $54.7 \%$ mothers from urban area practiced feeding during mothers illness in contrast to the $64 \%$ mothers of rural area who did not give feeds if mother had illness, 92\% mothers in both area had nutritious food during lactation (Table 3).

Table 1: Demographic variables of mothers $(\mathrm{N}=150)$.

\begin{tabular}{|c|c|c|c|c|c|}
\hline \multirow{2}{*}{ Variables } & \multirow{2}{*}{ Categories } & \multicolumn{2}{|c|}{ Urban mothers $(\mathrm{N}=\mathbf{7 5})$} & \multicolumn{2}{|c|}{ Rural mothers $(\mathrm{N}=75)$} \\
\hline & & $\mathbf{F}$ & $\%$ & $\mathbf{F}$ & $\%$ \\
\hline \multirow{3}{*}{ Age (in years) } & $18-25$ & 44 & 58.7 & 38 & 50.7 \\
\hline & $26-35$ & 30 & 40 & 32 & 42.7 \\
\hline & $36-40$ & 1 & 1.3 & 5 & 6.7 \\
\hline \multirow{4}{*}{ Educational qualifications } & No formal education & 7 & 9.3 & 9 & 12 \\
\hline & Primary education & 23 & 30.7 & 36 & 48 \\
\hline & Secondary education & 21 & 28 & 21 & 28 \\
\hline & Degree level education & 24 & 32 & 9 & 12 \\
\hline \multirow{4}{*}{ Occupation } & Government employee & 1 & 1.3 & 4 & 5.9 \\
\hline & Private employee & 22 & 29.3 & 23 & 30 \\
\hline & Self-employed & 8 & 12 & 5 & 5.3 \\
\hline & Housewife & 44 & 57 & 43 & 56.7 \\
\hline \multirow{3}{*}{ Source of information } & Mass media & 4 & 5.3 & 19 & 25.3 \\
\hline & Health professional & 43 & 57.3 & 19 & 25.3 \\
\hline & Family and friends & 28 & 37.3 & 37 & 49.3 \\
\hline \multirow{2}{*}{ Type of family } & Nuclear & 29 & 38.7 & 30 & 40.0 \\
\hline & Joint family & 46 & 60.7 & 45 & 59.3 \\
\hline \multirow{4}{*}{ Birth order of child } & $1 \mathrm{st}$ & 26 & 34.7 & 40 & 53.3 \\
\hline & 2nd & 32 & 42.7 & 27 & 36.0 \\
\hline & $3 \mathrm{rd}$ & 13 & 17.3 & 8 & 10.7 \\
\hline & 4th & 4 & 5.3 & - & - \\
\hline \multirow{3}{*}{$\begin{array}{l}\text { Who persuaded to give } \\
\text { first milk to the newborn? }\end{array}$} & Self & 22 & 29.3 & 17 & 22.7 \\
\hline & Elders & 21 & 34.7 & 36 & 48.0 \\
\hline & Health personnel & 27 & 36.0 & 22 & 29.3 \\
\hline
\end{tabular}

Table 2: Level of knowledge of mothers $(\mathrm{N}=150)$.

\begin{tabular}{|lllll|}
\hline \multirow{2}{*}{ Level of knowledge } & \multicolumn{2}{c|}{ Urban mothers $(\mathbf{N}=\mathbf{7 5})$} & \multicolumn{2}{c|}{ Rural mothers (N=75) } \\
\hline Inadequate $(\mathbf{< 5 0 \% )}$ & $\mathbf{F}$ & $\mathbf{\%}$ & $\mathbf{F}$ & $\mathbf{\%}$ \\
\hline Moderate (50-75\%) & 4 & 5.3 & 17 & 22.7 \\
\hline Adequate $(\mathbf{7 5 \% )}$ & 35 & 46.7 & 30 & 48 \\
\hline
\end{tabular}

Table 3: Colostrum feeding practices of mothers.

\begin{tabular}{|c|c|c|c|c|c|c|c|c|}
\hline \multirow{3}{*}{ Practices } & \multicolumn{4}{|c|}{ Urban mothers $(\mathbf{N}=\mathbf{7 5})$} & \multicolumn{4}{|c|}{ Rural mothers (N=75) } \\
\hline & \multicolumn{2}{|c|}{ Yes } & \multicolumn{2}{|c|}{ No } & \multirow{2}{*}{$\begin{array}{l}\text { Yes } \\
\text { F }\end{array}$} & \multicolumn{3}{|c|}{ No } \\
\hline & $\mathbf{F}$ & $\%$ & $\mathbf{F}$ & $\%$ & & $\%$ & $\mathbf{F}$ & $\%$ \\
\hline Colostrum feeding & 69 & 92 & 6 & 8 & 67 & 89.3 & 8 & 10.7 \\
\hline Colostrum feeding within one hour of delivery & 65 & 86.7 & 10 & 13.3 & 54 & 72 & 21 & 28 \\
\hline Pre-lacteal feeds given & 16 & 21.3 & 59 & 78.7 & 17 & 22.7 & 58 & 77.3 \\
\hline Burping after feed & 66 & 88 & 9 & 12 & 37 & 49.3 & 38 & 50.7 \\
\hline
\end{tabular}




\begin{tabular}{|c|c|c|c|c|c|c|c|c|}
\hline \multirow{3}{*}{ Practices } & \multicolumn{4}{|c|}{ Urban mothers ( $\mathrm{N}=\mathbf{7 5})$} & \multicolumn{4}{|c|}{ Rural mothers (N=75) } \\
\hline & Yes & & No & & Yes & & No & \\
\hline & $\mathbf{F}$ & $\%$ & $\mathbf{F}$ & $\%$ & $\mathbf{F}$ & $\%$ & $\mathbf{F}$ & $\%$ \\
\hline Colostrum feed given if newborn was sick & 50 & 66.7 & 25 & 33.3 & 54 & 72 & 21 & 28 \\
\hline $\begin{array}{l}\text { Colostrum feeding when mother had illness } \\
\text { during pre or postnatal period }\end{array}$ & 41 & 54.7 & 34 & 45.3 & 27 & 36 & 48 & 64 \\
\hline Nutritious food during lactation & 69 & 92 & 6 & 8 & 69 & 92 & 6 & 8 \\
\hline
\end{tabular}

Table 4: Difference in knowledge and practice scores between groups $(\mathrm{N}=150)$.

\begin{tabular}{|lllllll|}
\hline & \multicolumn{2}{l}{ Urban } & mothers $(\mathbf{N}=\mathbf{7 5})$ & \multicolumn{2}{l|}{ Rural mothers $(\mathbf{N}=\mathbf{7 5})$} & \multicolumn{2}{l|}{$\begin{array}{l}\text { Unpaired t } \\
\text { Variables }\end{array}$} & Mean & SD & Mean & SD & P value \\
\hline Knowledge & 14.65 & 3.38 & 12.65 & 3.66 & 4.168 & $0.000052^{* *}$ \\
\hline Practice & 5.013 & 1.01 & 4.33 & 1 & 8.607 & $<0.00001^{* *}$ \\
\hline
\end{tabular}

**Highly significant at 0.0001 level.

Table 5: Correlation between knowledge and practice of colostrum feeding ( $N=150)$.

\begin{tabular}{|c|c|c|c|c|c|c|c|c|}
\hline \multirow{2}{*}{ Variables } & \multicolumn{5}{|c|}{ Urban mothers ( $\mathbf{N = 7 5 )}$} & \multicolumn{3}{|c|}{ Rural mothers $(\mathrm{N}=75)$} \\
\hline & Mean & SD & $R$ value & $P$ value & Mean & SD & $R$ value & P value \\
\hline Knowledge & 14.45 & 3.38 & \multirow{2}{*}{0.351} & \multirow{2}{*}{$0.002 *$} & 12.05 & 3.66 & \multirow{2}{*}{0.178} & \multirow{2}{*}{0.124} \\
\hline Practice & 5.01 & 1.01 & & & 4.33 & 1 & & \\
\hline
\end{tabular}

*Significant at 0.05 level.

An unpaired $\mathrm{t}$ test was carried out to compare the difference of knowledge as well as practice scores in between the groups. There was a statistically significant difference in mean knowledge and mean practice scores regarding colostrum feeding between the mothers of urban and rural area which was found to be highly significant at 0.0001 level. The knowledge and practice scores among urban mothers was higher compared to the rural mothers (Table 4).

The Karl Pearson correlation was calculated to assess correlation between knowledge and practice scores. The correlation was found to be a weak positive, but significant in both the groups at $p<0.05$ level. In the rural area the correlation was not significant (Table 5).

Chi square test for association showed that there was an association between knowledge and practice scores of mothers regarding colostrum feeding and their level of education and monthly income in the urban PHC area. It was significant at 0.05 level $(\mathrm{p}<0.05)$. In the group of rural area mothers, the variable knowledge and practice had association with the age of mothers and type of family $(\mathrm{p}<0.05)$.

\section{DISCUSSION}

Infant mortality is registered as significantly high in developing countries like India. WHO and UNICEF enhances the cost effective measures through breastfeeding practice to bring down the mortality and morbidity rate. But the importance attached with colostrum feeding practice is being neglected by many mothers due to their ignorance and inadequate knowledge. So this study aimed to bring out and compare knowledge and practice regarding colostrum feeding among mothers in urban and rural areas at Bengaluru.

The present study findings indicated that most mothers (46.7\% urban, $48 \%$ rural) had a moderate level of knowledge and $22.7 \%$ mothers from rural area had inadequate knowledge. This can be associated with the fact that the educational status of the mother was low. Most had either primary or secondary level education. Our finding is in contrast to the finding of the study of Ekambaram et al who reported that the overall level of knowledge regarding colostrum feeding was very poor (88\%) among the study subjects and co-related significantly with higher maternal age and education. ${ }^{6}$ Another comparative study by Geetha with a lesser sample size reported level of knowledge as moderate (urban 56\%, rural 60\%). ${ }^{4}$ Balogun et al observed that the mothers in the urban area $(84.7 \%)$ had correct knowledge of the usefulness of colostrum compared with $68.5 \%$ in the rural area. ${ }^{7}$ Dhale et al study showed that $70 \%$ mothers had good knowledge. ${ }^{8}$ The respondents with a good level of knowledge of breastfeeding in the urban and rural areas were $84.7 \%$ and $89.5 \%$, respectively.

In the present study majority of the mothers in both areas (92\% urban, $89.3 \%$ rural) practiced colostrum feeding, which is higher. According to other studies, practice of colostrum feeding was comparatively lower (Shashank et al 67.6\%), 9 (Madhu et al 67\%) 10, (Yadav 95.8\% urban and $69.4 \%$ rural) ${ }^{9-11}$

Early initiation of breastfeeding refers to the initiation of breastfeeding within one hour after birth and ensures that 
the infant receives the colostrum, or first milk, which is rich in protective factors. ${ }^{12}$ In the current study most (86.7\% urban, $72 \%$ rural) of the mothers reported feeding colostrum within one hour after delivery. This is in contrast to the findings by Kumar et al who found $21.37 \%$ mothers from rural area and Bagul et al reported $32.56 \%$ urban mothers had started breastfeeding within one hour. ${ }^{13,14}$ Yadav et al reported significantly higher proportion of urban mothers initiated breastfeeding within one hour compared to rural mothers $(71.8 \%$ versus $54.2 \%) .{ }^{11}$ Balogun et al (75.8\% rural versus $43.5 \%$ urban) initiated breastfeeding immediately after birth. ${ }^{7}$

The present study showed that the practice of pre-lacteal feeding was observed to be prevalent in both urban and rural area mothers (21.3\% urban and $22.7 \%$ mothers). Other studies have reported a higher percentage of mothers giving pre-lacteal feeds. Ashwini et al (urban $54.25 \%$ and rural $57.11 \%$ ), Madhu et al (33\% of rural mothers), Yadav et al $(50.2 \%$ rural versus $18.4 \%$ of urban), Bagul et al (78.6\%). ${ }^{5,10,11,14}$ Chaturvedi et al (urban $78.9 \%$ versus rural $83.1 \%)$, Cheedarla et al $(32 \%$ urban), Jayarama et al (32.03\%). ${ }^{15-17}$

Burping the baby after feed which is an important measure to prevent GI disturbances such as colic and aspiration in newborn was lacking. In the current study burping after the feed was done by $88 \%$ mothers from urban area, whereas nearly half the mothers from rural area did not carry out burping. Cheedarla et al reported practice of burping after the breastfeeding was followed by $71 \%$ urban mothers. ${ }^{16}$ The assessment of the practice of burping has not been covered by many studies.

In the present study $66.7 \%$ and $72 \%$ mothers reported feeding the baby during illness in urban and rural area, respectively. Colostrum provides antibodies specifically targeting to fight newborn's illness. Colostrum contains protective antibodies to prevent infections in the newborn and provides vital nutrients for tissue development, growth and energy. The process of breast feeding itself is extremely comforting to a sick baby and a major part of the healing process. With regard to this fact one-fourth of the mother did not feed their baby during illness. According to an extensive review study by Paintal et al on feeding practices for infants and young children during and after common illness, it is described that, when sick, most children (up to 98\%) continue to be breastfed although a significant proportion (up to 49\%) is breastfed less frequently than usual. ${ }^{18}$ Few sick children $(<20 \%)$ are breastfed more frequently than usual, as is recommended.

Ideally, all newborns must get colostrum to avail the benefits as reported in literature which was lacking in this study in the of mothers of urban and rural area. In the current study higher percentage of mothers from rural area $(64 \%)$ did not feed during mother's illness in contrast to the $45.3 \%$ mothers from urban areas. It reveals that illness in the mother was a barrier to colostrum feeding in rural area. According to a review report by Lamounier et al when the nursing mother presents with the symptoms of a disease, she has already exposed her infant to the pathogen and the usual recommendation is that breastfeeding should be maintained. ${ }^{19}$ If the mother discontinues breastfeeding after symptom onset, infant protection against diseases is decreased and the chances of the infant falling ill are increased, since he/she is not provided with specific antibodies and other protective factors from human milk. No recommendation to discontinue breastfeeding, even if temporarily, exist in cases of mothers with urinary tract infection, bacterial infection of the abdominal wall, episiorrhaphy, mastitis or any other disease in which the nursing mother's physical conditions and general state of health are not so compromised.

In the present study overwhelming majority (92\%) mothers in both area stated that they had nutritious food during lactation which was quite satisfactory. Breast milk is the best food for newborn and infants. The nutrients present in this milk come from the diet of the mother or from her nutrient reserves. The conversion of nutrients in food, to nutrients in breast milk is not complete. To have good nutritional status, the breastfeeding woman has to increase the nutrient intake as reported by Segura et al. ${ }^{20}$

Comparison of knowledge and practice in the present study showed that there was difference in knowledge and practices of colostrum feeding which was found to be statistically significant. This may be attributed to the factors such as educational level of mothers in urban area was higher and mothers sought information from health professionals. Similar finding was observed by Subhalakshmi et al who found statistically significant difference between rural and urban areas with regard to the practice of feeding colostrum. ${ }^{21}$ A review of colostrum feeding practice by Mukherjee et al worldwide, indicated that the practice of discarding colostrum was influenced by women's social circumstances, such as education, region of residence, failing to attend antenatal clinic during pregnancy, delivery at home, lack of family support, discouragement of giving colostrum by traditional birth attendants, inadequate nutritional knowledge and adherence to cultural practice. ${ }^{22}$

A low positive correlation between knowledge level and practice of mother in urban area demonstrated that practices are influenced by the level of knowledge. There was an association between knowledge and practice of mothers regarding colostrum feeding and the level of education and economic status of mothers in the urban area $(p<0.05)$. In the group of rural area mothers the variable knowledge and practice had association with the age of mothers and type of family $(p<0.05)$. Whereas Kakati et al found a statistical association between colostrum feeding practices and age of the mothers, religion, type of family and educational status. ${ }^{23}$ 
The present study findings showed that mothers from both urban and rural areas lacked knowledge regarding colostrum feeding. Lacunae was found in a higher percentage of mothers from rural area compared to the mothers from urban areas. With regard to the practice of colostrum feeding, there were significant differences between the urban and rural mothers. Health care providers in hospitals as well as community based workers play a key role in changing the health behaviour of people towards colostrum feeding. Public awareness is an important factor for achieving health and practicing healthy feeding. This study reveals the need for providing information, education and communication (IEC) to mothers on colostrum feeding to improve knowledge and practice of people living in rural and urban community areas. It is also recommended to involve and educate the close family members in the IEC programs regarding colostrum and breastfeeding as the significant others in family are involved in providing care to the mother and newborn in the post-natal period. One to one counselling during the antenatal and immediate postnatal period regarding specific benefits of colostrum will help in improving knowledge and practice toward colostrum feeding.

\section{CONCLUSION}

The present study concluded that the knowledge regarding colostrum feeding was inadequate and improper colostrum feeding practices was observed in both urban and rural areas. In view of the current finding, it is recommended to put effort on promoting the benefits of colostrum feeding in both urban and rural area with a greater focus on rural area. Raising awareness in the community at large is also vital for community participation. Frequent and ongoing educational activity should be carried out to bring positive change.

\section{Funding: No funding sources}

Conflict of interest: None declared

Ethical approval: The study was approved by the institutional ethics committee

\section{REFERENCES}

1. John R. Knowledge, attitude and practice of employed mothers about breastfeeding. Nurs J India. 2005;96(4):85-6.

2. Joshi SK, Barakoti B, Lamsal S. Colostrum feeding: knowledge, attitude and practice in pregnant women in a teaching hospital in Nepal. Int J Mol Med. 2012.

3. Kumari S, Saili A, Jain S, Rhargava U, Gandhi G, Seth P. Maternal attitude and practices in initiation of newborn feeding. Ind J Pediat. 1988;55(6):905-11.

4. Geetha C. Knowledge and practice of colostrums and exclusive breast feeding among mothers of children below six month. Int J Adv Res. 2015;3(5):1511-8.

5. Ashwini S, Katti SM, Mallapur MD. Comparison of breast feeding practices among urban and rural mothers: a cross-sectional study. Int J Med Pub Heal. 2014;4(1):120-4.

6. Ekambaram M, Bhat VB, Ahamed MA. Knowledge, attitude and practice of breastfeeding among postnatal mothers. Curr Pediatr Res. 2010;14(2):11924.

7. Balogun MR, Okpalugo OA, Ogunyemi AO, Sekoni AO. Knowledge, attitude and practice of breastfeeding: a comparative study of mothers in urban and rural communities of Lagos, Southwest Nigeria. Nigerian Med J. 2017;58(4):123-30.

8. Dhale P, Mahakalkar M. A study to assess the knowledge and attitude regarding importance of colostrum among postnatal mothers in selected hospitals. Int J Sci Res. 2017;6(8):2239-41.

9. Shashank KJ, Chethan TK. A study on breastfeeding practices among mothers in rural area of mangalore district: a cross-sectional study. Ntl J Commun Med. 2016;7(2):134-7.

10. Madhu K, Chowdary S, Masthi R. Breast feeding practices and newborn care in rural areas: a descriptive cross-sectional study. Ind $\mathrm{J}$ Commun Med. 2009;34(3):243-6.

11. Yadav YS, Yadav S, Rathi S, Dhaneria M, Poonam Singh. Comparison of Infant feeding practices among rural and urban mothers: an observational study. Int J Med Res Rev. 2015;3(6):547-52.

12. WHO. Fact sheet: Support for mothers to initiate and establish breastfeeding after childbirth, 2019. Available

at: https://www.who.int/elena/titles/breastfeeding_suppo rt/en/. Accessed 12 April 2021.

13. Kumar S, Jha SK, Singh A, Rawat CM, Awasthi S, Bano M, et al. Knowledge, attitude and practices (kap) regarding breastfeeding: a community based cross sectional study from rural Uttrakhand. Healthline J. 2015;6(2):83-92.

14. Bagul AS, sahebrao Supare M. The infant feeding practices in an urban slum of Nagpur, India. J Clin Diagn Res. 2012;6(9):1525-7.

15. Chaturvedi M, Nandan D, Gupta SC. Rapid assessment of infant-feeding practices in Agra district. Ind J Commun Med. 2007;32(3):227.

16. Cheedarla V, Kenche B, Vemuri JLN, Reshaboyina LRL. A study on breast feedingmpractices among mothers in urban field practice area of tertiary care center, Hyderabad. Int J Commun Medi Pub Health. 2019;6(2):870-4.

17. Jayarama S, Ramaiah R. Pre lacteal feeding practice among mothers in a rural area of Karnataka: a cross sectional study. Int $\mathrm{J}$ Commun Med Pub Heal. 2017;4(8):2919-23.

18. Paintal K, Aguayo VM. Feeding practices for infants and young children during and after common illness. Evidence from South Asia. Matern Child Nutr. 2016;12(1):39-71.

19. Lamounier JA, Zeina S. Moulin ZA, Xavier CC. Recommendations for breastfeeding during maternal infections. Jornal de Pediatria. 2004;80(5):181-8. 
20. Segura SA, Ansótegui JA, Díaz-Gómez NM. The importance of maternal nutrition during breastfeeding: do breastfeeding mothers need nutritional supplements. An Pediatr (Barc). 2016;84(6):347.

21. Subhalakshmi G, Udipi SA, Nirmalamma N. Feeding of colostrum in urban and rural areas of Maharashtra and Gujarat. Ind J Pediatr. 1990;57(2):191-6.

22. Mukherjee K, Das K. Colostrum feeding practices worldwide: a review. Int J Curr Res. 2016;8(01):25796-9.
23. Kakati R, Rahman SJ, Borah M, Borah H. Colostrum feeding practices and its determinants among urban and rural mothers in Kamrup, Assam, India. Int J Res Med Sci. 2016;4(10):4567-72.

Cite this article as: Tejaswini S, Balakrishna BB. Comparison of knowledge and practice regarding colostrum feeding among mothers in rural and urban area. Int J Reprod Contracept Obstet Gynecol 2021;10:2347-53. 